\title{
Breve esbozo de los procesos de asimilación de los eslavismos al castellano
}

\author{
Bohdan ULAŠIN \\ Universidad Comenio de Bratislava (Eslovaquia) \\ bohdan.ulasin@gmail.com
}

Recibido: Octubre de 2011

Aceptado: Enero de 2012

\section{Resumen}

El artículo ofrece un breve esbozo de los cambios de adaptación a los que se ven sometidos los eslavismos que entran en el léxico español, empezando por la adaptación gráfica y fónica, pasando por la gramatical y semántica hasta la adaptación completa del préstamo.

Palabras clave: extranjerismo, préstamo, asimilación, eslavismo, signos diacríticos, caracteres cirílicos.

A Brief Outline of the Assimilation Processes of Slavic Loanwords into Spanish

\begin{abstract}
The article provides a brief outline of the adaptation changes the Slavic loanwords undergo on their way to form the part of the Spanish vocabulary, starting with the graphic and phonic adaptation through the grammatic and semantic one and ending with the complete adaptation of the loanword.
\end{abstract}

Key words: foreignism, loanword, assimilation, slavism, diacritical marks, Cyrillic script.

\section{Préstamo vs. extranjerismo}

La diferencia entre préstamo / adaptación y extranjerismo se remonta al siglo XIX, cuando en la lingüística alemana aparece la dicotomía de Lehnwort y Fremdwort. El extranjerismo es la palabra recién llegada cuyo origen extranjero es evidente tanto en la forma de la palabra como en el significado, que normalmente se refiere a un concepto ajeno a la comunidad lingüística en cuestión. Con el tiempo y la asimilación gradual la palabra acaba convirtiéndose en un elemento "orgánico" de la lengua. La frontera no está definida de forma precisa, la condicionan varios factores como el grado de asimilación fónica, ortográfica y gramatical y la percepción y conciencia lingüísticas de los hablantes. En el grupo de los préstamos adaptados al español encontramos palabras del árabe como zanahoria, aceite o almohada (su primera presencia en español está registrada en los años 1475, 1251 y 1335 respectivamente) COROMINAS (1987: 621, 24, 44) o del francés como flecha, jaula, jardín (en los años 1397, 1251 y 1495) COROMINAS (1987: 275, 343, 344). Por otro lado, en los galicismos o anglicismos relativamente recientes como boîte, chic, mitin, software, todavía se siente su origen extranjero y, por lo tanto, pertenecen a los extranjerismos. 
El proceso de asimilación de la palabra extranjera y su paso de los extranjerismos a los préstamos adaptados se puede observar en todos los niveles de la lengua. No obstante, este proceso es individual y su duración varía en cada caso. En las siguientes páginas trataremos de esbozar este proceso con especial enfoque en los eslavismos basándonos en el esquema de Juan GÓMEZ (2005: 14-27).

\section{Primera etapa: la palabra en el momento de la transferencia}

Casi nunca se conoce la fecha de la primera aparición de la palabra extranjera, normalmente la empiezan a difundir los que dominan el idioma originario del préstamo. En esta primera etapa la palabra está buscando su sitio, tiene que familiarizarse con el sistema ortográfico, fonético y gramatical de la lengua de acogida. Es característico el uso ocasional e individual que va creciendo poco a poco, primero en el seno de los especialistas y/o conocedores del campo léxico al cual se refiere la palabra en cuestión.

Dice Gómez sobre esta primera etapa de asimilación que:

(...) la palabra extranjera (...) aún no es comprendida por los hablantes de la lengua receptora, los sectores socio-profesionales que la han tomado se ven obligados a explicar su significado mediante marcas autonímicas; se trata de sinónimos, paráfrasis o explicaciones...: es un concierto unplugged, es decir, sin instrumentos eléctricos. GÓMEZ CAPUZ (2005: 16).

Es muy frecuente también el hecho de pasar sólo un significado de la palabra a la lengua de acogida, las demás denotaciones y connotaciones no siempre se transfieren, por ejemplo spútnik / espunique en ruso no significa sólo satélite sino también 'acompañante', 'concomitante', o la palabra stick del inglés stick ha entrado en español sólo con el significado de 'palo de hockey' (en inglés también 'vara', 'ramita', 'astilla', 'cartucho' (de dinamita, etc.) ${ }^{1}$.

A veces algunos extranjerismos son rechazados por la lengua y desaparecen, por ejemplo muchos galicismos medievales: sage 'sabio', follia 'locura', trobar 'encontrar' (TRUP 1993: 81); otros nunca sobrepasan la frontera entre un extranjerismo y un préstamo adaptado, no entran en la segunda etapa de la asimilación, se encuentran en la periferia del vocabulario y suelen utilizarse en contextos específicos, $\mathrm{p}$. ej. para describir o analizar el ambiente y la realidad del país de cuya lengua proceden. Es notable que este es el caso de muchos eslavismos con un estatus de términos específicos de poco alcance general y con el proceso de adaptación gráfica no completo. Son palabras como gulag $m$, glasnost $f$, perestroika $f \ldots$ que se refieren al ámbito político de la época de la Unión Soviética.

\footnotetext{
${ }^{1} \mathrm{http} / /$ www.wordreference.com/es/translation.asp?tranword=stick [17-10-2011].
} 


\section{Segunda etapa: proceso de asimilación del extranjerismo}

Si la palabra no ha sido rechazada y sigue difundiéndose entre los usuarios de la lengua, llega la fase de la adaptación a todos los niveles lingüísticos para integrarse y llegar a ser compatible con su "nuevo domicilio". Como afirma Gómez:

Una palabra extranjera comienza esta segunda etapa siendo todavía un extranjerismo y la termina siendo ya un préstamo, formalmente asimilado, ampliamente usado y apenas sentido como extranjero por muchos hablantes de la lengua receptora. (GÓMEZ CAPUZ 2005: 17).

\subsection{Asimilación gráfica}

Las palabras extranjeras se someten al proceso asimilatorio que las acerca al inventario fonológico español, lo que queda plasmado en la grafía: spaghetti > espagueti, buffet $>$ bufete, etc. No obstante, hay que decir que ante la creciente oleada de préstamos, sobre todo del inglés, el proceso asimilatorio se deja a medio terminar y acaban aceptándose algunas estructuras foráneas: pop, playback, handicap...

\section{Observaciones eslavas:}

Se observan los mismos principios en cuanto aañol a través de otras lenguas (francés e inglés sobre todo, a veces también a través del alemán), por lo que muchas veces ocurre que la asimilación gráfica ya se realiza allí: bolchevique $m>$ francés bolchevique $>$ ruso большевик (aunque hay que decir que el fonema postalveolar fricativo $s h$ en el ruso representado con el grafema ш equivale al fonema francés cuya representación gráfica es $c h$, lo que en español se pronuncia como una semioclusiva linguopalatal $t c h$ ); corbata $f>$ italiano corbatta o crobatta $>$ croata Hrvat 'croata'.

En cuanto al grado de adaptación, sólo en unos cuantos eslavismos muy frecuentes y/o presentes en español ya hace mucho observamos una adaptación completa $^{2}$ : corbata, esclavo, bohemio, zar, obús. En general, cuanto más se utiliza la palabra, tanto más fuerte suele ser la tendencia a adaptarla. Al castellanizar la pronunciación, los sonidos inexistentes en español se asemejan a los más parecidos: croata ustaša /ústa $\int a />$ ustacha $f$ /ustácha/ 'organización croata de ideología fascista fundada por Ante Pavelić'. También encontramos grafías no asimiladas del todo al sistema español: slivovitz $m$ 'aguardiente de plumas', perestroika $f$ 'reformas del sistema soviético puestas en marcha en los años ochenta por Mijaíl Gorbachov'.

En cuanto al ruso, ucraniano, bielorruso, búlgaro, macedonio y parcialmente el serbio $^{3}$, el proceso de adaptación ortográfica se ve afectado por el hecho de que estas lenguas no utilizan los caracteres latinos. Y no teniendo un modelo gráfico latino que

\footnotetext{
2 No sólo en español, sino también en las lenguas intermediarias, como se puede ver en el párrafo anterior.

${ }^{3}$ Se utilizan los dos sistemas de escritura en Serbia (p. ej. los nombres de las calles o los grandes periódicos suelen aparecer en dos mutaciones: cirílica y latina), mientras que en Montenegro y en Bosnia y Herzegovina predomina el uso de la escritura latina, en Croacia el alfabeto cirílico no se usa en absoluto. Lo importante, sin embargo, es que todos los caracteres cirílicos del serbio tienen sus variantes latinas y por eso podemos incluir en la mayoría de los casos las palabras del serbio, en cuanto a la asimilación gráfica al español, al grupo de lenguas con escritura latina.
} 
respetar, el español suele emplear con más libertad sus pautas gráficas. El problema surge con los sonidos de las lenguas eslavas inexistentes en español. He aquí una lista de los sonidos "problemáticos" más frecuentes con los cambios que suelen sufrir en el proceso de su transliteración al castellano:

a) la semioclusiva linguoalveolar sorda /ts/ (grafema ц) se transcribe del cirílico como $t s$ : trotskismo $m$ 'ideología marxista en oposición contra el estalinismo, representada por León Trotsky'. Mientras que el mismo sonido en las lenguas que emplean los caracteres latinos normalmente no cambia: cyrilovita $f$ 'mineral, $\mathrm{NaFe}_{3}^{3+}{ }_{3}\left(\mathrm{PO}_{4}\right)_{2}(\mathrm{OH})_{4} \cdot 2\left(\mathrm{H}_{2} \mathrm{O}\right){ }^{4}$ (en checo se pronuncia /tsírilovita/). Hay también palabras que primero pasaron por el alemán en el cual se produjo el cambio (/c/ eslava equivale más o menos a la alemana gráficamente representada por $t z$ ) y así pasó también al español: slivovitz $m$ 'aguardiente de ciruelas';

b) la semioclusiva linguopalatal sorda /t $\int /$ (grafema ч) se transcribe como $c h$ : oprichnik $m$ 'jefe del dominio territorial de oprichnina establecido por el zar Iván el Terrible'. En las lenguas de alfabeto latino (grafemas $\check{c}$ en checo, eslovaco, esloveno, croata, alto lusaciano; $c z$ en polaco), ole quita el signo

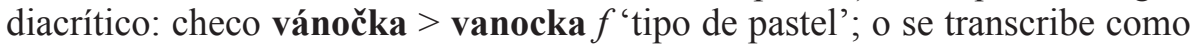
$c h$ o incluso $t c h$ : brichka $f$ 'tipo de carruaje tradicional', tchuvatch $m$ 'raza de perro pastor'; o bien la norma vacila: checo koláče $\rightarrow$ kolace / kolache $m$ $p l$. También en este caso, si el eslavismo ha sido intermediado por el alemán, se mantiene la transliteración alemana $\rightarrow$ tsch: tschermigita $f$ 'mineral, $\left(\mathrm{NH}_{4}\right) \mathrm{Al}\left(\mathrm{SO}_{4}\right)_{2} \cdot 12\left(\mathrm{H}_{2} \mathrm{O}\right)^{\prime}$ ' (de la variante alemana Tschermich del topónimo checo Cermiky);

c)la semioclusiva linguoalveolar sonora /dz/ (grafemas дз o dz), que existe sólo en polaco, eslovaco y bielorruso, queda sin cambios: bryndza 'tipo de queso de oveja salado', rendzina 'tipo de suelo';

d) la semioclusiva alveopalatal sonora $/ \mathrm{d} z /$. Existe en serbio (†), croata (đ), macedonio (Í): a veces se transcribe como $d j$ que es una de las maneras tradicionales como se escribía en croata antes de adoptar el sistema ortográfico actual, o se emplea $d$ y a veces : Djurdjevdan $m$ 'la Fiesta de San Jorge en Serbia', djuvec $m$ 'tipo de estofado balcánico de verdura y ternera';

e) la fricativa velar $/ \mathrm{x} /($ grafema $x$ ) se transcribe como $j$, aunque a veces podemos encontrar la transcripción inglesa $k h$ : koljós / kolkhós $m$ 'granja colectiva durante la Unión Soviética'. Los grafemas latinos (ch en checo, polaco, eslovaco, lusaciano; $h$ en esloveno, croata) no cambian: sahovnica $f$ 'escudo nacional croata en forma de un damero cuadriculado rojiblanco';

f) la fricativa linguoalveolar sorda / $/$ / (grafema $ш$ ) se transcribe del cirílico como $s h$ o sch: borscht $m$ 'sopa de verduras de la Europa Oriental'. De los alfabetos eslavos (grafemas $\check{s}$ en checo, eslovaco, esloveno, croata, lusaciano; $s z$ en polaco) de base latina, bien se adapta al sonido español $\mathrm{ch} / \mathrm{t} \int /$ : ustacha $f>$ croata ustaša [usta $\int a$ ], bien no cambia (empleando o no el signo diacrítico): sahovnica $f>$ croata šahovnica; o se transcribe con sh: hodrushita $f^{\prime}$ mine-

\footnotetext{
${ }^{4}$ Las fórmulas químicas de los minerales están tomadas de Korbel (2003).
} 
ral, $\mathrm{Cu}_{8} \mathrm{Bi}_{12} \mathrm{~S}_{22}$ '> derivación del topónimo eslovaco Hodruša;

g) la fricativa linguoalveolar sonora / $/$ / (grafema ж) se transcribe bien como $z h$ : druzhina $f^{\prime}$ 'entre los eslavos orientales de la edad media, tropas selectas para servir a un caudillo', bien como $j^{5}$ : mujik $m$ 'campesino ruso antes de 1917'. En las lenguas con alfabeto latino (grafema $\check{z}$ en checo, eslovaco, croata, esloveno, lusaciano; $\dot{z}$ en polaco) se le suele quitar el signo diacrítico: zywiec $m$ 'cerveza polaca'

h) las demás palatalizaciones gráficas no se suelen transcribir: ni el signo $b$ cirílico: ruso гласность $>$ glasnost $f^{\prime}$ 'política de transparencia llevada junto con la perestroika'; ni el anticircunflejo de los caracteres latinos ( () : checo

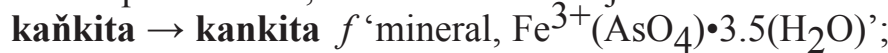

i) los demás signos diacríticos de los caracteres latinos tampoco se transcriben: polaco złoty > zloty $m$ 'moneda polaca';

j) en español normalmente se les quitan los signos diacríticos a los préstamos de las lenguas de alfabeto latino (checo, eslovaco, polaco, esloveno, croata, alto lusaciano). Hay que decir, no obstante, que la norma en este caso vacila. Por ejemplo, en las entradas de la Wikipedia suelen aparecer las dos formas, con los signos diacríticos y sin ellos: checo vánočka $\rightarrow$ esp. vánočka / vanocka; en la mayoría de los diccionarios y periódicos estos signos desaparecen6: checo háček $\rightarrow$ hacek $m$ 'carón, anticircunflejo'. Los textos oficiales de la Unión Europea, p. ej. los Reglamentos que adopta el Consejo Europeo para proteger las denominaciones de origen de productos agrícolas ${ }^{7}$ son el otro extremo, no hay cambios en los préstamos de caracteres latinos: Slovenská parenica $f$ 'tipo de queso eslovaco', oštiepok $m$ 'tipo de queso ahumado'; con las lenguas que usan el cirílico estos textos utilizan la transcripción inglesa: Бургаска Мускатова ракия > Bourgaska Muscatova rakya tipo de aguardiente de Bulgaria';

k) el grafema $k$ se sustituye por $c$ en las palabras plenamente adaptadas o en los eslavismos de etimología grecolatina: ucraniano козак > cosaco $m$, ruso космонавт > cosmonauta $m$; mientras que en las palabras poco frecuentes no cambia: vodka, mujik, kolache. Aparecen también vacilaciones de grafía: troika / troica 'triunvirato';

1) el sonido $/ \mathrm{j} /$ : en las lenguas eslavas de alfabeto latino se emplea el grafema $\mathrm{j}$, lo que suele mantenerse y a veces lleva a los hispanohablantes a pronunciarlo erróneamente como /x/: eslovaco fujara $f$ 'instrumento de viento del folklore tradicional eslovaco'. De las lenguas de alfabeto cirílico ( $j$ en serbio y macedonio, й en las demás) se reemplaza bien por la i latina, creando así una combinación ajena que no se da en las palabras vernáculas: rus. perestroika, troika / troica 'triunvirato', matrioska 'muñeca rusa'; bien por la y griega al principio de la palabra o en la posición intervocálica: efecto $m$ Yarkovsky

\footnotetext{
${ }^{5}$ Las fórmulas químicas de los minerales están tomadas de Korbel (2003).

${ }^{6}$ Quizá por la influencia francesa, donde el grafema $j$ se pronuncia casi idénticamente a la ж rusa.

Esta problemática requeriría una investigación más detallada basada en una recopilación de datos y su análisis estadístico, lo que no es el objetivo principal de nuestro trabajo.

${ }^{7} \mathrm{http}$ ://ec.europa.eu/agriculture/quality/door/list.html [17-10-2011].
} 
'efecto que modifica la órbita de los asteroides y meteoroides', boyardo $m$ 'noble terrateniente ruso, búlgaro, serbio o rumano';

m) las vacilaciones no afectan sólo a los signos diacríticos, a veces para escribir una palabra se utilizan más formas gráficas que difieren en el nivel de adaptación: intelligentsia / inteliguentsia $m$ 'élite intelectual de la sociedad'.

Al margen de este capítulo, en los antropónimos también podemos observar la tendencia de mantener la forma gráfica latina de los nombres propios procedentes de lenguas con escritura latina. Muchas veces se pierden los signos diacríticos: Slobodan Milosevic $>$ del serbio Slobodan Milošević. Por otra parte, con los nombres de grafía cirílica no se toma en cuenta su forma originaria, se busca la forma de caracteres latinos que alcance la mayor fidelidad acústica en español: Mijaíl Gorbachov, Dostoievski, Jrushchov, Yéltsin, Yivkov, etc ${ }^{8}$.

\subsection{Asimilación fónica}

Según observa Gómez Capuz (2005: 19-21) los extranjerismos introducidos por vía escrita (es patente sobre todo en los préstamos de las lenguas con un gran desfase entre la grafía y la pronunciación como es el caso del inglés y francés) reciben la pronunciación española de la grafía extranjera: folklore/folklore/,jersey/xerséi/. Es el caso de los préstamos más antiguos.

Por otro lado, en el caso de los préstamos introducidos por vía oral se imita la pronunciación extranjera, aunque muchas veces imperfecta, llegando así a un lógico compromiso entre la pronunciación original y las posibilidades fónicas del español: beige [beis], playback [pleibak], jazz [yas].

\section{Observaciones eslavas:}

Lo que es válido para la asimilación gráfica también lo es para la asimilación fónica, cuanto más frecuente y antiguo es el eslavismo, mayor presión existe con el fin de adaptarse al español: ruso царь [토ar'] > zar $m$ vs. ruso троцки́зм [trotskízm] > trotskismo $m$. En los eslavismos poco frecuentes de lenguas con alfabeto latino no suele cambiar la ortografía, lo que crea muchos escollos y malentendidos, ya que los grafemas latinos en las lenguas eslavas pueden tener una pronunciación bien diferente: serbio y croata polje $>$ poljé $m$ 'tipo de elemento típico de la zona cárstica' que debería pronunciarse [po $\lambda \mathrm{e}]$ y no [polxe] porque los grafemas $l j$ en serbio y croata corresponden a un fonema líquido lateral prepalatal $/ \lambda /$, o sea, a la /1/ palatalizada; el eslovaquismo fujara debería pronunciarse $\mathrm{y}$, completada la adaptación, también escribirse de la siguiente manera /fuyara/; tamburica $f$ 'instrumento de cuerda tradicional de los Balcanes similar a la mandolina' del serbio es [tamburitsa]; el polonismo pierogi $m p l$ 'tipo de pasta rellena' [pierogui], etc. ${ }^{9}$

\footnotetext{
8 Es destacable que, por ejemplo en eslovaco (checo, croata, esloveno...), que también usa caracteres latinos, la transcripción es bien diferente, debido a í los nombres de los cuatro políticos mencionados en la transcripción eslovaca: Michail Gorbačov, Chruščov, Jel'cin, Živkov.

9 Todos estos ejemplos con su grafía no española están recopilados de las entradas de la Wikipedia.
} 


\subsection{Asimilación gramatical}

Para poder funcionar en el sistema gramatical el préstamo debe adquirir las categorías gramaticales obligatorias.

Observaciones eslavas:

Los sustantivos en las lenguas eslavas tienen tres géneros: masculino, femenino y neutro. Por lo tanto, los préstamos eslavos originalmente neutros cambian de género: Politburó $m$ 'máximo órgano ejecutivo de los partidos políticos, sobre todo de los partidos comunistas', dobro $m$ 'guitarra resofónica', zemstvo $m$ 'unidad administrativa en Rusia de 1864 a 1917', aquí la forma de las palabras con la vocal final $-o$, típica del género neutro eslavo, ha sido asignada al género masculino español precisamente por el hecho de que la mayoría de los sustantivos españoles terminados en $-O$ son masculinos (el gato, el vaso, el dinero, el edificio, el bolígrafo, etc.). En caso de otra vocal final típica del neutro eslavo, la $-e$, la conciencia lingüística de los españoles admite los dos géneros (el coche, el pie, el sobre, la clase, la carne, la fiebre, la noche), así que la asamblea popular de los eslavos en la época medieval (neutra en eslavo) puede ser perfectamente femenina en español: veche $f^{\prime}$ 'asamblea popular de los eslavos de la Edad Media'. Aunque el sustantivo neutro serbio y croata polje se ha convertido en español en un nombre masculino: poljé $m$.

En cuanto a los sustantivos originalmente masculinos o femeninos, éstos no suelen cambiar: el robot, la perestroika, la corbata, la dolina, etc. Nunca cambian de género, claro está, los sustantivos con el género natural (palabras que se refieren a personas): husita $m$, zar $m$. No obstante conocemos también ejemplos de cambio de género, p. ej. el caso de las bebidas alcohólicas de género femenino en las lenguas eslavas: becherovka $m$, vodka ${ }^{10} m$ (se trata de la tendencia homogeneizante de la clase de los aguardientes: el tequila, el güisqui, el coñac...).

También en la formación del plural hay muchas excepciones, como consonante + s: los kulaks 'campesinos ricos'; la forma del singular y plural es idéntica (y no lo es en la lengua originaria): los apparátchik 'funcionario profesional (de la administración soviética)', los samizdat 'textos ilegales, clandestinos durante la censura soviética'; se forma el plural según la lengua de origen: el panelak 'casa de paneles de hormigón prefabricadas' - los panelaky. Los verbos se integran a la primera conjugación en -ar: tunelar 'defraudar fondos comunes', esclavizar.

\subsection{Asimilación semántica}

Como afirma GÓMEZ (2005: 24-25) muchas veces la palabra extranjera tiene un significado que guarda ciertas similitudes semánticas con otras palabras nativas. En este caso de sinonimia parcial el extranjerismo y las palabras afectadas ya existentes suelen pasar por el proceso de (la) especialización semántica: el extranjerismo adquiere el significado marcado y el equivalente nativo mantiene un valor más amplio: capo del italiano 'jefe' $\rightarrow$ 'jefe mafioso' vs. jefe (antiguo galicismo ya plenamente incorporado) con su significado genérico; o se reparten el área de signifi-

\footnotetext{
${ }^{10}$ Aunque la RAE acepta ambos géneros: http://buscon.rae.es/drael/SrvltConsulta?TIPO_BUS=3\&LEMA=vodka [17-10-2012].
} 
cación: el anglicismo póster se usa para los carteles de ornamentación de interiores y el cartel (un antiguo catalanismo plenamente adaptado) para los que tienen finalidad política o reivindicativa.

\section{Observaciones eslavas:}

Muchos de los eslavismos son términos que no tienen equivalente, se han tomado precisamente para cubrir una laguna semántica, por lo tanto se añaden al léxico receptor sin competir con las palabras patrimoniales: chernozém 'tipo de suelo negro rico en humus', semtex 'explosivo plástico', mazurca 'baile tradicional polaco'; bolchevique, slavikita 'mineral, $\mathrm{MgFe}_{3}\left[(\mathrm{OH})_{3}\left(\mathrm{SO}_{4}\right)_{4}\right] \cdot 18 \mathrm{H}_{2} \mathrm{O}$ ', etc.

\section{Préstamo adaptado}

El extranjerismo, al adaptarse plenamente a todas las pautas de la lengua receptora, se convierte en un elemento integral del léxico y, como tal, suele estar sujeto a la generación de nuevos elementos según las necesidades de la lengua de acogida.

Observaciones eslavas:

A esta etapa llegan relativamente pocos eslavismos, normalmente los más antiguos y los más frecuentes. Están sujetos a la creación neológica a través de los:

\section{Mecanismos morfosintácticos}

a) derivación: robot $\rightarrow$ robotización, robótica, robótico; esclavo $\rightarrow$ esclavitud, esclavizar;

b) recomposición: robot $\rightarrow$ telerrobótica, nanorrobot, biorrobótica, microrrobot, semiesclavo;

d) cruce: robot $\rightarrow$ domobot 'microbot domótico', nanobot 'nanorrobot';

e) unidades sintagmáticas: robot $\rightarrow$ cirugía robótica, robot de cocina.

\section{Mecanismos semánticos:}

Consiste en la alteración o añadidura de otro significado al significado originario, sea a otro sema a través de una metáfora o metonimia. Muy pocos eslavismos crean otros significados aparte de los que ya tenían a la hora de entrar en el léxico español: sputnik $m$ 'satélite' $\rightarrow$ lenguaje de los drogadictos 'hachís de excelente calidad' SANMARTÍN (2006: 758).

\section{Referencias bibliográficas}

COROMINAS, J. (1987): Breve diccionario etimológico de la lengua española, Madrid, Gredos.

GÓMEZ CAPUZ, J. (2005): Inmigración léxica, Madrid, Arco Libros. 
KORBEL, P. - NOVÁK, M. (2003): Enciclopedia de los minerales, Madrid, Libsa. SANMARTÍN SÁEZ, J. (2003): Diccionario de argot español, Madrid, Espasa, 2006. TRUP, L. (1993): Úvod do štúdia španielskeho jazyka, Bratislava, Filozofická fakulta UK. ULAŠIN, B. (2011): "Eslovaquismos y bohemismos en español", Eslavística Complutense, 11, pp. 73-83.

\section{Referencias en línea}

Door - Comisión Europea: http://ec.europa.eu/agriculture/quality/door/list.html [17-10-2011]. RAE - Diccionario de la lengua española: http://www.rae.es http://buscon.rae.es/draeI/SrvltConsulta?TIPO_BUS=3\&LEMA=vodka [17-10-2012]. Wikipedia: http://www.wikipedia.org http://es.wikipedia.org/wiki/Fujara [17-10-2012]. http://es.wikipedia.org/wiki/Pierogi [17-10-2012].

http://es.wikipedia.org/wiki/Poljé [17-10-2012]. http://es.wikipedia.org/wiki/Tambura [17-10-2012].

Wordreference: http://www.wordreference.com/es/translation.asp?tranword=stick [17-10-2011]. 